\title{
Biomaterials
}

\section{Crack growth resistance of alumina, zirconia and zirconia toughened alumina ceramics for joint prostheses}

\author{
A.H. De Aza ${ }^{\mathrm{a}}$, J. Chevalier ${ }^{\mathrm{a}, *}$, G. Fantozzi ${ }^{\mathrm{a}, *}$, M. Schehl ${ }^{\mathrm{b}}$, R. Torrecillas ${ }^{\mathrm{b}}$ \\ ${ }^{a}$ GEMPPM (Materials Department), UMR CNRS 5510, National Institute for Applied Sciences, INSA de Lyon, 20 Avenue Albert Einstein, \\ 69621 Villeurbanne Cedex, France \\ ${ }^{\mathrm{b}}$ INCAR, Spanish Research Council (CSIC), La Corredoria s/n Ap.73, 33080 Oviedo, Spain
}

Received 1 November 2000; accepted 11 June 2001

\begin{abstract}
Mono-phase bio-ceramics (alumina and zirconia) are widely used as femoral heads in total hip replacements (THR) as an alternative to metal devices. Unfortunately, the orthopaedic community reports significant in-vivo failures. Material scientists are already familiar with composites like alumina-zirconia. Since both are biocompatible, this could prove to be a new approach to implants. This paper deals with a new generation of alumina-zirconia nano-composites having a high resistance to crack propagation, and as a consequence may offer the option to improve lifetime and reliability of ceramic joint prostheses. The reliability of the above mentioned three bio-ceramics (alumina, zirconia and zirconia toughened alumina) for THR components is analysed based on the study of their slow crack-growth behaviour. The influence of the processing conditions on the microstructure development, of the zirconia toughened alumina composites and the effect of these microstructures, on its mechanical properties, are discussed. (C) 2001 Published by Elsevier Science Ltd.
\end{abstract}

Keywords: Zirconia toughened alumina; Alumina; Zirconia; Total hip replacements; Slow crack growth; Threshold

\section{Introduction}

In modern surgery, total hip replacement using prostheses constitutes a state-of-the-art operation. Nowadays, these implants have an average lifetime of about 10 years. However, considering an ageing population and the growing demand on performing orthopaedic surgery on younger patients, implants should be designed for long-term applications and thus, should exhibit a lifetime of more than 30 years. All implants have also to be very reliable and fracture in-vivo is not acceptable.

Ceramic materials are now becoming an alternative to the common metal femoral heads articulating against an acetabular cup of polyethylene, or to metal-metal bearing devices. These materials appear to be ideally suited for joint prosthesis, because of their hardness, which means in turn low wear rates and an excellent biocompatibility. The use of bio-ceramic materials, in comparison to metal alloy structural implants, provides

*Corresponding author. Fax: +33-4-72-43-8528.

E-mail address: jerome.chevalier@insa-lyon.fr (J. Chevalier). less wear rate of the implant polyethylene components and produces negligible amounts of metal ion release. In fact, abrasion in the artificial joint can lead to loosening of the implant due to the osteolysis caused by polyethylene wear particles [1-3]. Abrasion can be reduced significantly if ceramic femoral heads are used with acetabular cups made of polyethylene. Abrasion is even least when using ceramic femoral heads together with ceramic cup inserts [4]. However, ceramic materials are known to be brittle and susceptible to slow crack growth (SCG) [5].

Currently, alumina ceramics, $\mathrm{Al}_{2} \mathrm{O}_{3}$, are widely used for bearing surfaces THR [6]. Their widespread use is based on a combination of good strength, modest fracture toughness, high wear resistance, good biocompatibility and excellent corrosion resistance. Unfortunately, significant in-vivo failure is reported by the orthopaedic community due to the slow crack growth that leads to failure of the alumina ceramic component with time in service [7]. In the pioneer times the fracture rate was quite high, mainly for alumina-alumina pairs. A recent compilation of cases studies show that the in vivo fracture ratio (number of fractures/number of 
implanted heads) of current-day alumina heads-polyethylene combinations can stand below $0.01 \%$ for the past ten years [7]. Nevertheless there is need to improve reliability.

Phase-stabilized zirconia has become a popular alternative to alumina as structural ceramic [8] because of substantially higher fracture toughness and strength. Pure zirconia cannot be used for fabricated ceramic forms without stabilisers additions [9]. The role of these phase-stabilisers is to retain the high-temperature phase, tetragonal, at room temperature, which gives zirconia its desirable properties as an engineering ceramic. The addition of yttria is used in zirconia orthopaedic implants. Phase-stabilized zirconia has the largest value of fracture toughness of any monolithic ceramic. Static and fatigue strengths for zirconia femoral heads have been found to satisfy clinical requirements [10]. Another reason for the THR application of zirconia, has been the decreased frictional torque and the reduced level of polyethylene debris production in a zirconia femoral head-polyethylene acetabular cup couple [11]. The wear performance, in this system, has been shown to be superior even to alumina [12,13]. However, again case studies show that delayed failure can occur in-vivo [14]. Another issue concerning zirconia is its hydrothermal stability. At the present time, it is known that yttria stabilised zirconia ceramics can be destabilised during the process of steam sterilisation, giving surface roughening of zirconia ceramic femoral heads, due to hydrothermal transformation [8]. These femoral heads may also undergo slow degradation during long term implantation in the human body. This low temperature degradation only is significant after several years $[15,16]$, but can question the use of zirconia-on-zirconia bearings systems.

A composite material is the way to improve reliability and lifetime of orthopaedic implants by providing higher fracture toughness and mechanical strength. Material scientists are already familiar with composites like alumina-zirconia. Since both materials are biocompatible, this could prove to be a new approach to implants [17].

Two kinds of composites can be prepared in this system: a phase-stabilized zirconia matrix reinforced with alumina particles, alumina toughened zirconia (ATZ) or an alumina matrix reinforced with zirconia particles, zirconia toughened alumina (ZTA). With both materials higher toughness values than with the monophase ceramics can be reached but higher values are expected for ZTA composites [18]. Additionally, in the case of a zirconia matrix, the problem related with hydrothermal stability will still remain due to the need of yttria to stabilise zirconia [19]. On the other hand, with an alumina matrix this addition can be avoided since the alumina matrix acts constraining the zirconia particles, retaining the tetragonal zirconia in a meta- stable state, toughening the ceramic host material $[19,20]$. Moreover, the hardness of composites with an alumina matrix will be greater, because alumina is harder than zirconia [7]. This should lead a priori to higher wear resistance.

In this paper, the reliability of the above mentioned three bio-ceramics for THR components is analyzed based on the studied slow crack-growth behaviour. The influence of the processing conditions on the microstructure development of the ZTA composites and the effect of these microstructures on its mechanical properties, are discussed.

\section{Theoretical background: fast failure and subcritical crack growth in ceramics}

\subsection{A matter of brittleness}

Ceramics are brittle by nature because they are sensitive to stress concentrations around pre-existing small defects, such as pores, scratches or cracks. Under an applied tensile stress, $\sigma$, the stresses at the tip of a crack can be described by the stress intensity factor $K_{I}$, given by

$$
K_{I}=Y \sigma \sqrt{a},
$$

where $a$ is the crack (or any pre-existing defect) length, and $Y$ a geometry factor related to the crack. It is generally assumed that fast fracture occurs with brittle materials if the stresses at the crack tip, represented by the above mentioned stress intensity factor $K_{I}$, become larger than the fracture toughness $K_{I C} . K_{I C}$ is related to the resistance to fast fracture.

Therefore, the fracture strength, $\sigma_{R}$, of a given ceramic specimen will be given by

$\sigma_{R}=\frac{K_{I C}}{Y \sqrt{a}}$.

An approach to the problem of brittle failure is to increase the toughness, generally by the development of composite materials. For a given material, an additional approach to obtain improved strength and reliability is to refine ceramic processing to produce homogeneous components with a defect size $(a)$ as small as possible. Refining powder processing to eliminate microstructural flaws from brittle bio-ceramics is possible to produce materials at the top end of their strength spectrum.

\subsection{Subcritical crack growth (SCG)}

$K_{I C}$ has provided the basis of the first theories of fracture. However, it is now well recognised that failure of ceramics can occur even when stressed under $K_{I C}$ (or $\sigma_{R}$ ). Indeed, $K_{I C}$ (and $\sigma_{R}$ ) only represent a critical level for fast crack growth. Ceramic materials are susceptible 
to slow crack propagation at $K_{I}$ values under $K_{I C}$ [5]. This phenomenon is often referred as 'subcritical crack growth' with respect to a crack propagation for stress intensity factors under the toughness. This subcritical crack growth is notable for its extreme sensitivity to applied load and it tends also to depend on concentration of environmental species, temperature, and other extraneous variables. That means that under appropriate conditions, cracks keep on growing for some time until they cause fracture without warning. Since it is not possible completely to avoid imperfections and microcracks during the production of sintered bio-ceramic materials, under these "appropriate" conditions, cracks will grow in a slow manner before the catastrophic failure.

As a general trend, slow crack growth is described on the basis of a $V$ (crack velocity) versus $K_{I}$ (stress intensity factor) diagram. Slow crack growth in bioceramics is attributed to stress assisted corrosion at the crack tip, or any pre-existing defect in the ceramic. This is indeed the combined effect of high stresses at the crack tip and the presence of water or body fluid molecules (reducing surface energy at the crack tip) that induce crack propagation in a subcritical manner [21]. Recently, the presence of a threshold in the stress intensity factor, under which no crack propagation occurs, has been the subject of important research in the ceramic field [22]. The threshold corresponds to a crack equilibrium with a null crack velocity, thus propagation does not occur. For ceramic joint prostheses, this threshold determines a safety range of use. The higher the threshold, the higher the reliability and consequently the lifetime. Here we will try to show that this threshold represents a more intrinsic property for a given material than the widely used toughness, which refers only to fast crack growth.

At this point it is useful to summarize the main features of the $V$ versus $K_{I}$ diagram, to set the stage for the theoretical descriptions in next sections. We do this schematically in Fig. 1. There are a number of features and different stages but as a general trend, a unique relationship can be established, for a given environment, between the crack velocity $(V)$ and the applied stress intensity factor $\left(K_{I}\right)$, with three different stages attributed to three distinct mechanisms [21]. For each stage, a power law can fit the speed at which a crack propagates when stressed.

$V=A K_{I}^{n}$,

where $A$ and $n$ are constants dependent on the material properties and environmental variables. $K_{I 0}$ defines a temperature-insensitive equilibrium state below which no crack growth occurs (region 0 in Fig. 1). This has been observed particularly in glasses and there is evidence of its occurrence in oxides [21]. It is clearly advantageous to establish the existence of such thresh-

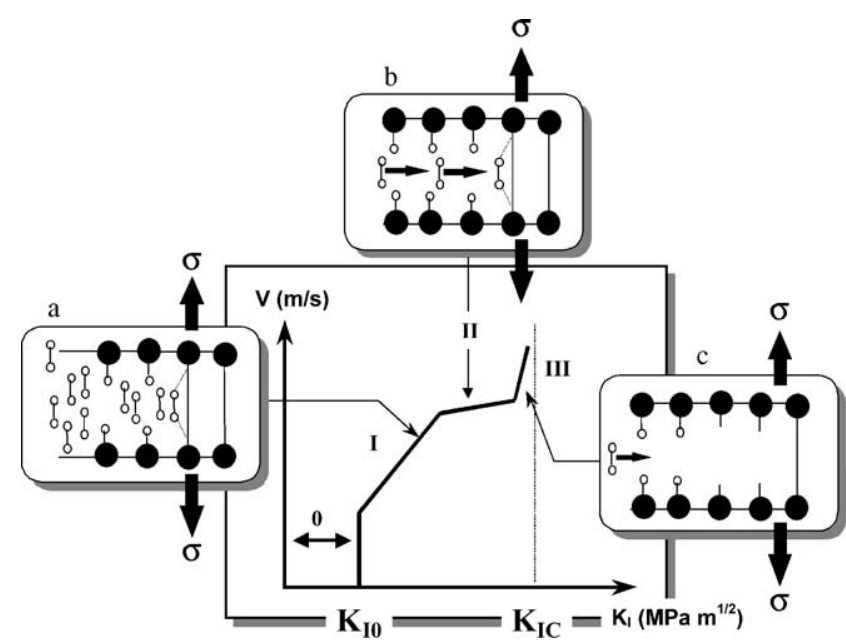

Fig. 1. $(\mathrm{a}-\mathrm{c})$. Schematic representation summarising the different crack velocity regions observed in experimental $V-K_{I}$ curves. See text for details.

old in order to define a perfectly safe region of operation. This, however, is not easy because the crack velocities involved are particularly low and there is a lack of experimental data in the scientific literature. Region I depends strongly on external variables, applied stress, temperature and chemical concentration. In this region, the environmental species react with the ceramic bonds in the crack front-tip, leading to a crack propagation, process schematically represented in Fig. 1a. This region is reaction-rate controlled. Region II is insensitive to applied stress, suggestive of a transport process in which the active environmental species are increasingly unable to keep pace with the crack front-tip as $K_{I}$ increases. Then this region depends on the diffusion of the corrosive species from the environment to the crack tip. See Fig. 1b. This intermediate branch thereby connects region I-III, which identifies with the velocity response in a vacuum. The increasing stress magnifies the crack velocity giving no time to the active environmental species to reach the crack front-tip. See Fig. 1c. Region III is associated with fast fracture and then with $K_{I C}$.

With the aim of clarifying the processes involved in stages I and II an idealised representation of a proposed reaction between a humid environment and a strained $\mathrm{Zr}-\mathrm{O}-\mathrm{Zr}$ bond at the crack tip is shown in Fig. 2. Reaction steps involve: (1) adsorption of water to $\mathrm{Zr}-\mathrm{O}$ bond, (2) reaction involving simultaneous proton and electron transfer, and (3) formation of surface hydroxyls.

In a water or simulated body fluid environment, only one stage is observed and the slope of the curve is similar to that of the first stage in air (region I), highlighting the environmental-corrosion influence in this domain [21]. On the other hand, in silicon oil or under vacuum environment, where no water molecules are present, the 


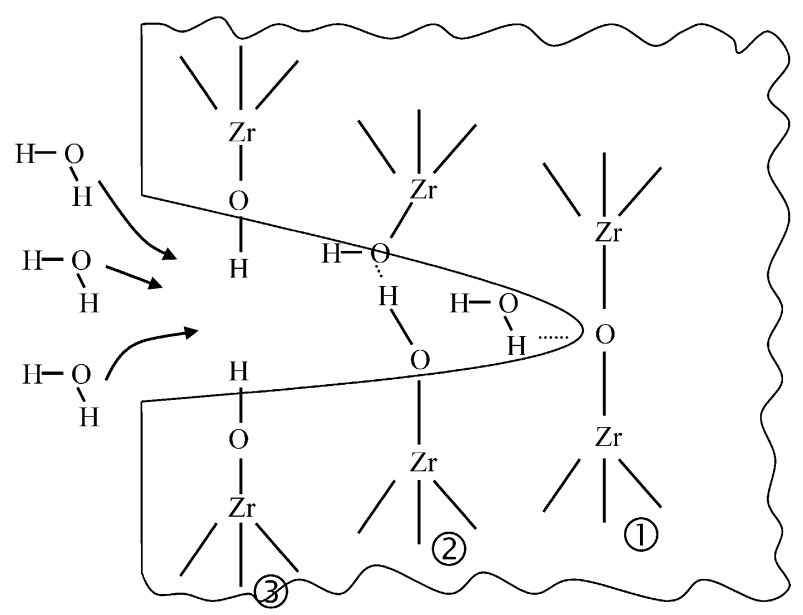

Fig. 2. Schematic representation of the proposed reaction between water and a strained $\mathrm{Zr}-\mathrm{O}-\mathrm{Zr}$ bond at the crack tip. Reaction steps involve: (1) adsorption of water to $\mathrm{Zr}-\mathrm{O}$ bond, (2) reaction involving simultaneous proton and electron transfer, and (3) formation of surface hydroxyls.

whole $V-K_{I}$ curve presents a much higher slope, similar to that of the region III, and the slow crack growth takes place only for stress intensity factors near the $K_{I C}$. This suggests that, in this stage, the stress is the dominant factor instead of corrosion. Fig. 3 shows a schematic description of the relation between crack velocity $V$, stress intensity $K_{I}$, and environment.

Therefore, crack propagation can be described using the relation (3). If the crack propagation parameters $(A$ and $n$ ) are known for each stage, it is possible to estimate the durability of a component. In any case, biocomponents should be designed to work in region 0 (under $K_{\mathrm{I0}}$ ), since in zones I-III delayed fracture will occur sooner or later.

\section{Experimental procedure}

\subsection{Materials}

Slow crack growth experiments were made on biomedical grade alumina (grain size: $1.7 \mu \mathrm{m}$, and $\approx 99 \%$ theoretical density), zirconia ( $3 \mathrm{~mol} \%$. yttria stabilized: 3 Y-TZP, with a grain size of $0.5 \mu \mathrm{m}$ and $\approx 99.9 \%$ theoretical density), and alumina-zirconia composites. Alumina and zirconia have already been studied, details of the experimental procedure and material features can be found elsewhere [21,23].

ZTA composites containing unstabilized zirconia were processed. A series of formulations were prepared in the range $0-15 \mathrm{vol} \% \mathrm{ZrO}_{2}$ and they were processed, either by conventional powder mixing-milling processing technique or a colloidal processing route.

In connection with the conventional mixing-milling technique a stable suspension, $\mathrm{pH} \approx 4$, in distilled water

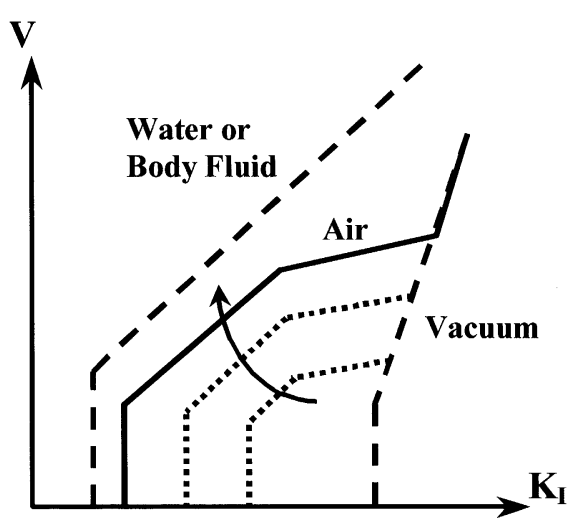

Fig. 3. Idealised representation showing the relation between crack velocity $(V)$, stress intensity $\left(K_{I}\right)$ and environment. As a general trend, an increase of the water content leads to a decrease of the threshold and an increase of crack velocities. The three crack propagation regimes, environmental-corrosion by water (region I), gas-diffusion controlled (region II), and vacuum conditions (region III) are present in air. Only one stage (region I) is present in water, because there is no crack rate limitation by water diffusion. Only Region III is present in oil or under vacuum (no environmental-corrosion by water).

of a high-purity ( $>99.9 \mathrm{wt} \%$ ) alumina powder ${ }^{1}$ (with an average particle size of $0.45 \mu \mathrm{m}$ and a surface area of $\left.10 \mathrm{~m}^{2} \mathrm{~g}^{-1}\right)$ was homogeneously mixed with a ( $>99.9 \mathrm{wt} \%$ purity) monoclinic zirconia powder ${ }^{2}$ (with a mean particle diameter of $0.47 \mu \mathrm{m}$ and a specific surface area of $15.5 \mathrm{~m}^{2} \mathrm{~g}^{-1}$ ). The batches were wet ground in a laboratory scale annular gap mill [24] with high-purity $3 \mathrm{~mm}$ alumina balls. Subsequently, they were spray-dried, and a quantitative X-ray diffraction (D5000-Kristalloflex 710, Siemens, Karlsruhe, Germany) was performed to ensure that there was no preferential loss of material during the spray-drying process. The final batches average particle size, measured by laser diffraction (Coulter LS 130), was between $0.33-0.4 \mu \mathrm{m}$.

In this investigation, a major research effort was concentrated in a new colloidal processing route of alumina-zirconia composites [25]. This processing route consists in doping a stable suspension of the above mentioned alumina powder in absolute ethanol $(99.97 \%)$ by dropwise addition of a diluted (2/3 vol\% $\mathrm{Zr}$ alkoxide, $1 / 3 \mathrm{vol} \%$ ethanol absolute) zirconium alkoxide. ${ }^{3}$ After drying under magnetic stirring at $70^{\circ} \mathrm{C}$, the powders were thermally treated at $850^{\circ} \mathrm{C}$ for $2 \mathrm{~h}$ in order to remove organic residuals and were subsequently attrition milled, as a suspension in alcohol, with $3 \mathrm{~mm}$ alumina balls for $1 \mathrm{~h}$. The powders were dried and sieved to less than $45 \mu \mathrm{m}$.

Batches were cold isostatically pressed to an initial shape at $200 \mathrm{MPa}$. The optimum sintering conditions

\footnotetext{
${ }^{1}$ Condea HPA- 0.5 , Ceralox division, Arizona, USA.

${ }^{2}$ Tosoh TZ 0, Tosoh corporation, Tokyo, Japan.

${ }^{3}$ Aldrich Zirconium -IV- propoxide $70 \mathrm{wt} \%$ solution in 1-propanol.
} 
were studied by means of dilatometric analysis (AdamelLhomargy DI-24). Final composites were sintered in air at $1550^{\circ} \mathrm{C}$ for $2 \mathrm{~h}$, leading to $98 \%$ theoretical density. The bulk density of the obtained materials was measured by Archimedes method. The sintered samples were cut $\left(2\right.$ by 20 by $\left.40 \mathrm{~mm}^{3}\right)$ and polished with a series of diamond pastes down to $1 \mu \mathrm{m}$. The average alumina and zirconia grain sizes were measured using SEM micrographs (Philips XL20) of polished and thermally etched surfaces using a linear intercept method (ASTM ${ }^{4}$ E112 standard test method) and using an image analyzer program (Scion Image, Scion corporation, Marylan, USA) where the diameter $d$, was calculated from the projected particle area $A$, using the well-known stereological expression

$d=2 \sqrt{A / \pi}$.

\subsection{Methods}

Crack velocities from $10^{-12} \mathrm{~m} \mathrm{~s}^{-1}$ (threshold) to $10^{-2} \mathrm{~m} \mathrm{~s}^{-1}$ (fast fracture) were measured by the double torsion technique. Details on the double torsion technique and the modus operandi during tests can be found in Ref. [26]. The double torsion specimens and the loading configuration are shown in Fig. 4. No guiding groove was machined in the specimens in order to avoid any residual stress intensity factor [27]. The tensile surface was polished down to $1 \mu \mathrm{m}$ in order to observe the crack with a precision of $\pm 2 \mu \mathrm{m}$. A notch of dimension $a_{0}=10 \mathrm{~mm}$ and root $\rho=0.1 \mathrm{~mm}$ was machined with a diamond saw and an indentation was performed at low load $(5 \mathrm{~kg})$ in order to initiate a small crack. Subsequent precracking was performed by loading the specimens at low rate in order to induce a 'real' sharp crack of initial length $a_{i}=12 \mathrm{~mm}$. The double torsion configuration is known for giving a stress intensity independent of crack length, given by

$K_{I}=\frac{W_{m}}{U^{2}}\left(\frac{3(1+v)}{W \psi}\right)^{1 / 2} P=H P$,

where $P$ is the load, $W_{m}$ the span, $W$ and $U$ the width and the thickness of the specimen, $v$ the Poisson ratio (taken here as equal to 0.3 ), and $\psi$ a calibration factor.

However, it has been recently demonstrated that $K_{I}$ was slightly dependent on the crack length [27], then to obtain accurate $V-K_{I}$ diagrams a correction factor should be introduced in the conventional expression of $K_{I}$. This correction is expressed with the following empirical equation:

$K_{I}=H P\left(\frac{a}{a_{0}}\right)^{6 / 32}$,

\footnotetext{
${ }^{4}$ American Society for Testing and Materials, West Conshohocken, PA.
}

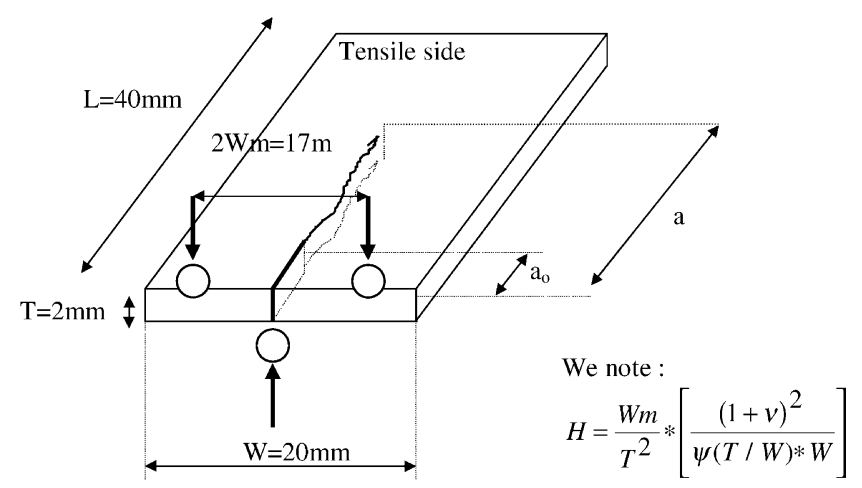

Fig. 4. Specimens dimensions and loading configuration for the double torsion test.

where $a_{0}$ is the notch length and $a$ is the total crack length.

Subcritical-crack-growth laws were determined via two methods: relaxation tests and constant-loading tests. The load-relaxation method, which was first reported by Williams and Evans [26], was used to obtain the slow crack growth $V-K_{I}$ diagrams in the velocity range $10^{-2}-10^{-7} \mathrm{~m} \mathrm{~s}^{-1}$. This method does not allow measurements at very low velocity but it does present the advantage of being fast to obtain measurements at high velocities. Pre-cracked specimens were loaded at a constant rate of $0.2 \mathrm{~mm} / \mathrm{min}$, followed by subsequent stopping of the cross-head at constant displacement, when crack started to propagate. The obtained load-relaxation versus time $(P$ versus $t)$ plot allows the determination of the $V-K_{I}$ curve by a compliance calibration [26,27].

Measurement of the crack velocities $V$ under constant load presents the advantage of allowing the measurement of very low velocities, down to $10^{-12} \mathrm{~m} / \mathrm{s}$. Thus, the specimens were subjected to different static loads under a prescribed duration $\Delta t$. The crack length was measured via optical microscopy, with a precision of $\pm 2 \mu \mathrm{m}$, and $V$ is defined as the ratio of crack increment $\Delta a$ to the duration $\Delta t$ :

$V=\Delta a / \Delta t$.

The results presented in the following sections were obtained on a minimum of two specimens for each materials. The variability from one specimen to another was low, as a consequence of a good processing reproducibility and of the refinements proposed by the authors on the double torsion method [27].

Hardness measurements were conducted with Vickers indentations at a load of $10 \mathrm{~N}$, on 10 different specimens for each material, with an automated testing machine (Teswell, Wolpert-Germany). An indentation load rate of $0.5 \mathrm{~N} / \mathrm{s}$ and a dwell time of $20 \mathrm{~s}$ were chosen. The hardness was automatically calculated from the ratio of the indentation load to the plastic deformation area. 


\section{Results and discussion}

Different proportions of alumina and zirconia were tested but only the results of the $10 \mathrm{vol} \%$ zirconia composition are discussed. The crack velocity diagram corresponding to the three bioceramics is shown Fig. 5. The results for the three polycrystalline ceramics show the typical three stages of SCG and a threshold below which no crack propagation occurs (cf. Section 2.2). The threshold $\left(K_{I 0}\right)$, was determined from the points on the $V-K_{I}$ diagram, below which there is an abrupt drop of the crack velocity, $V<10^{-12} \mathrm{~m} \mathrm{~s}^{-1}$ (see Fig. 5). On the other hand, the toughness $\left(K_{I C}\right)$ was determined by extrapolation of the $V-K_{I}$ curve to high crack velocities, $10^{-2} \mathrm{~ms}^{-1}$ (see Fig. 5). Their values are represented in Table 1 for the three bioceramics.

Contrasting results are underlined here for alumina and zirconia ceramics. Zirconia exhibits a higher toughness than alumina but their thresholds are close, meaning that the necessary crack tip stress to initiate crack growth is roughly the same in both materials. Conversely, the alumina-zirconia nanocomposite not only has a slightly higher toughness than zirconia, but also a much higher threshold, a consequence of a higher slope of its $V-K_{I}$ diagram.

The high toughness of zirconia ceramics is attributed to the stress induced phase transformation of metastable tetragonal grains towards the monoclinic symmetry ahead of a propagating crack, leading to an increase of the work of fracture [28]. This phenomenon of transformation toughening relies on the volume expansion, $3-5 \%$, and shear strain $\approx 7 \%$ developed when tetragonal zirconia transforms to the monoclinic form [29]. The stabilisation of tetragonal phase is thought to arise from a combination of surface energy effects, constraints of the rigid matrix and stabilising oxide additions, e.g. yttria [28]. Transformation can occur locally once the constraints are removed, in this case when the crack propagates.

Alumina has lower susceptibility to water and thus to stress assisted corrosion. As a consequence, the $V-K_{I}$ curve of alumina presents a higher slope than the curve corresponding to zirconia. Even if alumina is intrinsically more brittle than zirconia (lower toughness), it exhibits a threshold of the same order. From an atomistic point of view, this means that the fracture energy of zirconia is lower in the presence of water or body fluid, because the zirconia bonds are prone to chemisorption of the polar water molecules (like silica glass for example). The addition of a small amount of zirconia (here $10 \mathrm{vol} \%$ ) to alumina has two main advantages. First, zirconia toughened alumina composites present crack propagation mainly through the alumina matrix. Thus, these composites possess a lower susceptibility to stress assisted corrosion by water or body fluid. Second, these materials are reinforced by the

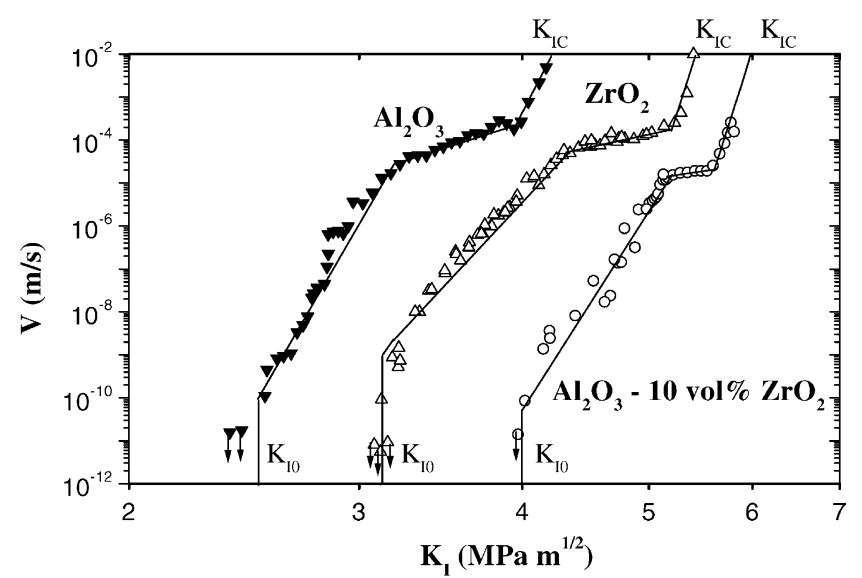

Fig. 5. Crack velocity $(V)$ versus stress intensity factor $\left(K_{I}\right)$ for biomedical grade $\mathrm{Al}_{2} \mathrm{O}_{3}, \mathrm{ZrO}_{2}$ and $\mathrm{Al}_{2} \mathrm{O}_{3}-10$ vol\% $\mathrm{ZrO}_{2}$ nanocomposite. The alumina-zirconia nanocomposite processed by the mentioned colloidal processing route exhibits the highest crack resistance. $\nabla \mathrm{Al}_{2} \mathrm{O}_{3} ; \triangle \mathrm{ZrO}_{2} ; \bigcirc \mathrm{Al}_{2} \mathrm{O}_{3}-10 \%$ vol. $\mathrm{ZrO}_{2}$. Arrows indicate tests were no propagation could be observed, crack rate must be lower than the value plotted.

Table 1

Fracture threshold $\left(K_{I 0}\right)$, toughness $\left(K_{I C}\right)$ and hardness $(H)$ values for the three bio-ceramics

\begin{tabular}{llll}
\hline Ceramic material & Threshold & Toughness & Hardness \\
& $K_{I 0}\left(\mathrm{Mpa} \mathrm{m}^{1 / 2}\right)$ & $K_{I C}\left(\mathrm{MPa} \mathrm{m}{ }^{1 / 2}\right)$ & $H$ (Vickers) \\
\hline Alumina $\left(\mathrm{Al}_{2} \mathrm{O}_{3}\right)$ & $2.5 \pm 0.2$ & $4.2 \pm 0.2$ & $1600 \pm 50$ \\
Zirconia $\left(\mathrm{ZrO}_{2}\right)$ & $3.1 \pm 0.2$ & $5.5 \pm 0.2$ & $1290 \pm 50$ \\
$\mathrm{Al}_{2} \mathrm{O}_{3}-10 \mathrm{vol}_{0} \mathrm{ZrO}_{2}$ & $4.0 \pm 0.2$ & $5.9 \pm 0.2$ & $1530 \pm 50$ \\
\hline
\end{tabular}

presence of highly transformable zirconia particles, shifting the $V-K_{I}$ diagram of alumina towards higher $K_{I}$ values. The authors have theoretically shown [30] in a previous work that the presence of small amounts of zirconia particles in a given matrix should lead to a shift of the $V-K_{I}$ diagram towards higher $K_{I}$ values, preserving the slope of the curve. The obtained results support definitively this theoretical prediction. This is of course only true if strong chemical bonding occurs between alumina and zirconia particles and if no microcracks are present after processing, which is the case of $10 \mathrm{vol} \%$ zirconia composites [20]. It has been shown that this zirconia content corresponds to a maximum toughening [20]. Above this critical content, microcracking occurs during cooling, associated with a decrease of the interface properties.

ATZ were not tested here. However, a low SCG resistance is expected, since propagation occurs in a zirconia matrix and the effect of transformation toughening will be negligible if $\mathrm{ZrO}_{2}$ is not stabilised with yttria to avoid the related hydrothermal stability problem.

At this point, it is important to stand out the primary objective of refining powder processing using the 


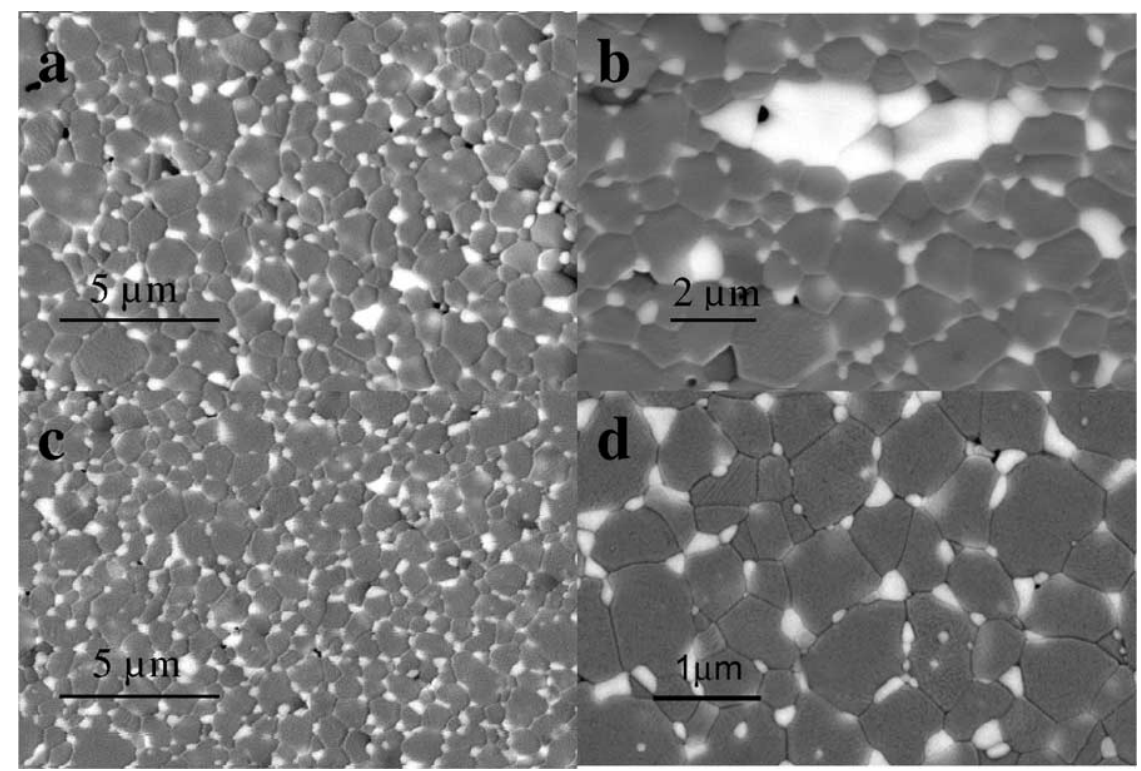

Fig. 6. (a-d). Scanning back-scattered electron microscopy images showing the microstructure of the $\mathrm{Al}_{2} \mathrm{O}_{3}-10$ vol\% $\mathrm{ZrO}_{2}$ nanocomposites obtained. $\mathrm{ZrO}_{2}$ grains (the brighter phase) homogeneously distributed in a fine grain $\mathrm{Al}_{2} \mathrm{O}_{3}$ matrix (the darker phase). a, b: conventional powder mixing-milling processing technique $\left(\mathrm{Al}_{2} \mathrm{O}_{3} D_{50}=1.7 \pm 0.6 \mu \mathrm{m}\right.$ and $\left.\mathrm{ZrO}_{2} D_{50}=0.7 \pm 0.4 \mu \mathrm{m}\right)$. c, d: described colloidal processing route $\left(\mathrm{Al}_{2} \mathrm{O}_{3}\right.$ $D_{50}=1.2 \pm 0.4 \mu \mathrm{m}$ and $\left.\mathrm{ZrO}_{2} D_{50}=0.4 \pm 0.1 \mu \mathrm{m}\right)$.

colloidal processing technique. Fig. $6 a-d$ show the final microstructure of the alumina $10 \mathrm{vol} \%$ zirconia composite obtained either by conventional powder mixingmilling processing techniques or a colloidal processing route, and Fig. 7 shows the zirconia particle size distribution obtained for both materials, assuming a normal distribution of zirconia particle sizes. Consequently, the aim is to obtain nano-sized $\mathrm{ZrO}_{2}$ particles homogeneously distributed, avoiding agglomerates, at the alumina grain boundaries and therefore minimize microstructural flaws. Likewise, due to the small size of the zirconia grains and its narrow grain size distribution (see Fig. 7), it is possible to retain a larger amount of tetragonal zirconia grains in the alumina matrix and this contributes to the transformation toughening mechanism operating in these composites.

It may be noted, as above mentioned that the colloidal processing route leads to more narrow zirconia grain size distribution compared with the conventional powder mixing technique (see Fig. 7). Thus, it is possible to obtain nano-sized particles in the range from the critical size for spontaneous transformation after sintering, $D_{c}$, (above which there is no reinforcement) to the critical size for transformation during crack growth, $D_{c}^{\prime}$, (below which there is no crack induced transformation, thus no reinforcement) [20,31-33]. Fig. 8 shows how this micostructural refining leads to a displacement of the $V-K_{I}$ diagram to higher $K_{I}$ values. Additionally, this colloidal processing route avoids the use of any stabilizing oxide, moving away the possibility of a hydrothermal low temperature degradation, observed in the case of zirconia bioceramics [8].

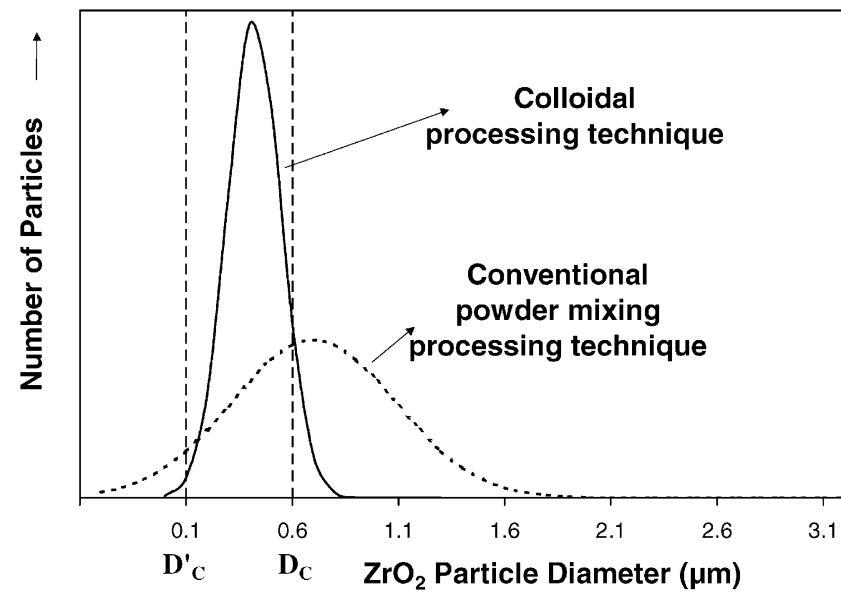

Fig. 7. $\mathrm{ZrO}_{2}$ grain size distribution in the alumina $10 \mathrm{vol} \%$ zirconia composites obtained either by conventional powder mixing-milling processing technique or a colloidal processing route (assuming a normal distribution of zirconia particle sizes). The narrow size distribution of the nanocomposite obtained by the colloidal processing route is between the critical size for spontaneous transformation after sintering $\left(D_{c}\right)$ and the critical size for transformation as crack growth $\left(D_{c}^{\prime}\right)$; which means that almost all the particles of $\mathrm{ZrO}_{2}$ present in the material are reinforcing the composite.

\section{Conclusions}

The following concluding remarks can be drawn:

1. For orthopaedic applications alumina-zirconia composites have a higher reliability than the monolithics (higher $K_{I 0}$ and $K_{I C}$ ) due to the combination of the 


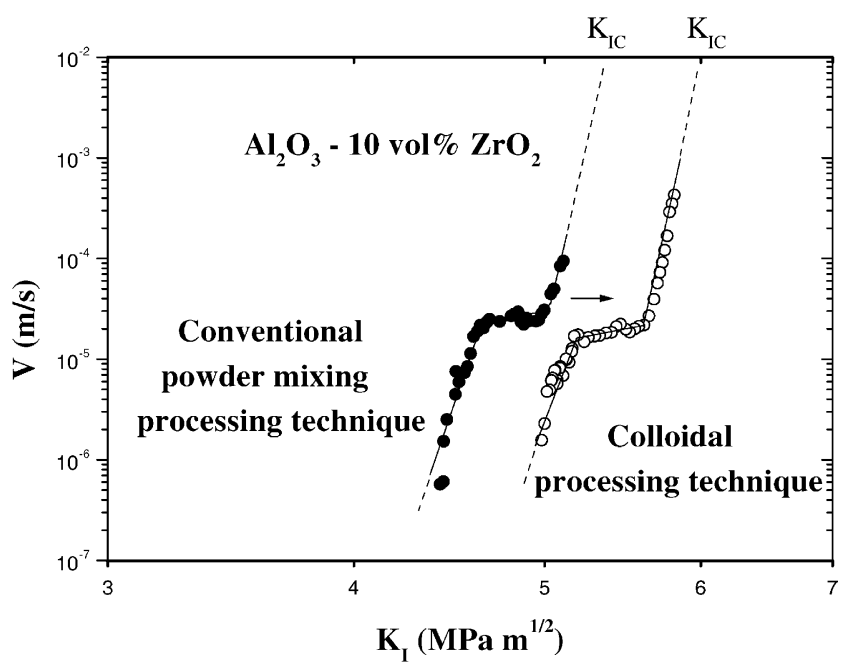

Fig. 8. Here, it can be seen how a refining of the microstructure, by using the described colloidal processing synthesis route, leads to a displacement of the $V-K_{I}$ diagram to higher $K_{I}$ values.

advantages of both, alumina and zirconia. For the same pre-existing defects, these composites can work at loads two times higher than monolithic alumina without delayed failure.

2. Hardness and stability are of prime interest in the orthopaedic field. Alumina-zirconia nanocomposites with relatively low zirconia contents $(10 \mathrm{vol} \%)$ present similar hardness values than alumina (see Table 1) and are not susceptible to the hydrothermal instability observed in the case of stabilised zirconia bioceramics (low temperature degradation).

3. Tailoring the microstructure by refining powder processing using a new colloidal processing synthesis route is possible to produce alumina-zirconia nanocomposites at the top end of they strength spectrum.

4. The microstructure of the alumina-zirconia composites obtained by the colloidal processing synthesis technique is very fine with submicrometer alumina grains and, mainly intergranular, nano-sized zirconia particles with a narrow grain size distribution. This leads to a high portion of tetragonal phase retained at room temperature (after sintering) with the ability to transform under applied stress. This indicates that the dominant toughening mechanism in these composites is transformation toughening.

5. Even though, other compositions, forming techniques and sintering conditions (e.g. hot isostatic pressing) should be further investigated in order to optimise mechanical properties. This nanomaterials may offer the option to improve the lifetime and reliability of ceramic femoral heads, so contributing to improve the quality of life of a large number of patients. Further surgical operations and consequently the suffering of people as well as the high cost of such operations will be avoided.
6. From a general point of view, the idea of a welldefined stress limit, toughness $\left(K_{I C}\right)$, particularly attractive in engineering design must incorporate the concept of a threshold $\left(K_{I 0}\right)$ under which crack propagation does not takes place. This threshold represents an intrinsic property for a given material that gives an information of its mechanical behaviour more realistic than the widely used toughness, which means only fast crack growth.

\section{Acknowledgements}

The authors wish to express their appreciation to J.L. Rodríguez and L.A. Diaz for his kind help with sample preparations. A.H. De Aza wishes to acknowledge financial support (PF 98 05271356) from the Ministry of Education and Culture of Spain.

\section{References}

[1] Schmalzried TP, Kwong LM, Jasty M, et al. The mechanism of loosening of cemented acetabular components in total hip artroplasty. Analysis of specimens retrieved at autopsy. Clin Orthop 1992;274:60-78.

[2] Schmalzried TP, Guttmann D, Grecula M, Amstutz HC. The relationship between the design, position and articular wear of acetabular components inserted without cement and the development of pelvic osteolysis. J Bone Jt Surg 1994;76A:677-88.

[3] Manley MT, Serekian P. Wear debris. Clin Orthop Related Res 1994;298:37-146.

[4] Villermaux F. Zirconia-alumina as the new generation of ceramic - ceramic THR: wear performance evaluation including extreme life conditions. Proceedings of 6th World Biomaterials Congress, Workshop on Zirconia Femoral Heads for Total Hip Prostheses, Kamuela, Hawaii, USA: Society for Biomaterials, 2000 .

[5] Lawn B. Fracture of brittle solids. Cambridge solid state science series. 2nd ed. UK: Cambridge university press, 1993, p. 378.

[6] Willmann G. Ceramic femoral heads for total hip arthroplasty. Advanced Eng Mater 2000;2:114-22.

[7] Heros R, Willmann G. Ceramics in total hip arthroplasty: history, mechanical properties, clinical results and current manufacturing state of the art. Seminars Arthroplasty 1998;9:114-22.

[8] Piconi C, Maccauro G. Zirconia as a ceramic biomaterial, a review. Biomaterials 1999;20:1-25.

[9] Hannink RH, Kelly PM, Muddle BC. Transformation toughening in zirconia-containing ceramics. $\mathbf{J}$ Am Ceram Soc 2000;83(3):461-87.

[10] Drouin JM, Cales B. Yttria-stabilized zirconia for improved hip joint head. In: Andersson ÖH, Yli-Urpo A, editors. Bioceramics 7. London: Butterworth-Heinemann Publisher, 1994. p. 387-94.

[11] Shackelford JF. Bioceramics. Advanced ceramics, vol. 1. Australia: Gordon and Breach science publishers, 1999. p. 83.

[12] McKellop H, Lu B. Friction, lubrication and wear of polyethylene/metal and polyethylene/ceramic hip prostheses on a joint simulator. Trans. 4th World Biomaterieals Congress. Berlin, Germany, 1992. p. 118.

[13] Kumar, Oka M, Ikeuchi K, Shimizu K, Yamamuro T, Okumura $\mathrm{H}$, Koloura Y. Low wear rates of UHMWPE against zirconia ceramic in comparison to alumina ceramic and SUS 316 alloy. J Biomed Mater Res 1991;25:813-28. 
[14] Hummer C, Rothman R, Hozack W. Catastrophic failure of modular zirconia-ceramic femoral head components after total hip arthroplasty. J Arthroplasty 1995;10:848-50.

[15] Chevalier J, Drouin JM, Cales B. Low temperature ageing behavior of zirconia hip joint heads. In: Sedel L, Rey C, editors. Bioceramics, Proceedings of the 10th International Symposium on Ceramics in Medicine, vol. 10. Amsterdam: Elsevier Ltd., 1997. p. $135-8$.

[16] Chevalier J, Cales B, Drouin JM. Low-temperature aging of YTZP ceramics. J Am Ceram Soc 1999;82(8):2150-4.

[17] Chevalier J, De Aza AH, Fantozzi G, Schehl M, Torrecillas R. Extending the lifetime of orthopaedic implants. Advanced Mater 2000;12(21):1619-21.

[18] Fantozzi G, Orange G. Thermomechanical properties of zirconia toughened alumina materials. In: Moya JS, De Aza S, editors. Processing of advanced ceramics. Soc Esp Ceram Vidr Arganda del Rey Madrid Spain, 1986. p. 187-215.

[19] Green DJ, Hannink RHJ, Swain MV. Transformation toughening of ceramics. Boca Raton, FL: CRS Press, Inc., 1989. p. 232.

[20] Claussen N. Fracture toughness of $\mathrm{Al}_{2} \mathrm{O}_{3}$ with an unstabilized $\mathrm{ZrO}_{2}$ dispersed phase. J Am Ceram Soc 1976;59(1-2):49-51.

[21] Chevalier J, Olagnon C, Fantozzi G. Subcritical crack growth in 3Y-TZP ceramics: static and cyclic fatigue. J Am Ceram Soc 1999;82(11):3129-38.

[22] Wan K, Lathabai S, Lawn BR. Crack velocity functions and thresholds in brittle solids. J Europ Ceram Soc 1990;6:259-68.
[23] Ebrahimi ME, Chevalier J, Fantozzi G. Slow crack growth of alumina ceramics. J Mater Res 2000;15:142-7.

[24] Cremer W. Defined grinding in a grinding chamber former as an annular gap. Interceram 1989;5:59-61.

[25] Schehl M, Torrecillas R. Alumina nanocomposites from powderalkoxide mixtures. Acta Mater 2001, accepted for publication.

[26] Williams D, Evans A. A simple method to study slow crack growth. J Testing Evaluation 1973;1:264-70.

[27] Chevalier J, Saadaoui M, Olagnon C, Fantozzi G. Double-torsion testing a 3Y-TZP ceramic. Ceramic Int 1996;22:171-7.

[28] Garvie RC, Hannink RH, Pascoe RT. Ceramic steel? Nature 1975;258:703-4.

[29] Stevens R, Evans P. Transformation toughening by dispersed polycrystalline zirconia. Br Ceram Trans J 1984;83:28-31.

[30] Chevalier J, Olagnon C, Fantozzi G. Crack propagation and fatigue in zirconia-based composites. Composites, part A 1999;30:525-30.

[31] Heuer AH, Claussen N, Kriven WM, Rühle M. Stability of tetragonal $\mathrm{ZrO}_{2}$ particles in ceramic matrices. J Am Ceram Soc 1982;65(12):642-50

[32] Messing GL, Kumagai M. Low-temperature sintering of seeded sol-gel-derived, $\mathrm{ZrO}_{2}$-toughened $\mathrm{Al}_{2} \mathrm{O}_{3}$ composites. J Am Ceram Soc 1989;72(1):40-4.

[33] Srdic VV, Radonjic L. Transformation toughening in sol-gelderived alumina-zirconia composites. J Am Ceram Soc 1997; 80(8):2056-60. 